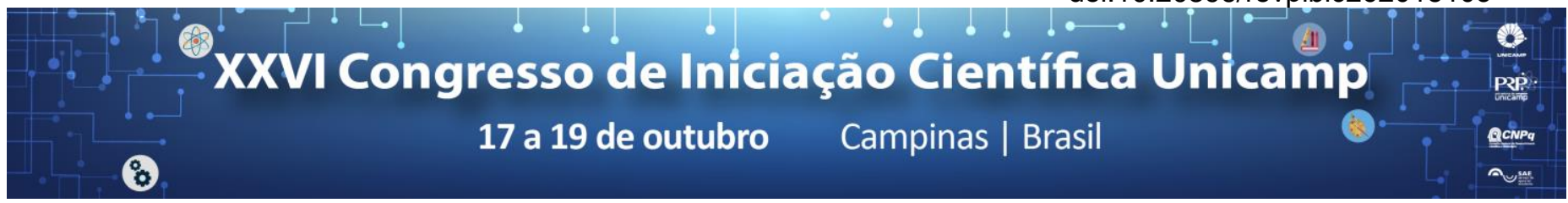

\title{
Morphological and physiological responses of Coffea arabica L. plants subjected to water restriction
}

\section{Amanda R. Lopes*, Julieta A.S. Almeida}

\begin{abstract}
Plants of seven genotypes of Coffea arabica cultivated in a greenhouse under two cycles of water restriction showed, in general, a high foliar wilt rate, a lower foliar temperature and a higher rate of electrolytic leakage than those continuously irrigated.
\end{abstract}

Key words: Leaf wilt, leaf temperature, electrolyte leakage

\section{Introduction}

The Coffea arabica L. species is adapted to climatic conditions in Brazil, which is the largest producer and exporter of coffee. However, Brazilian coffee may be hampered by climate change resulting from global warming, such as drought. Drought reduces coffee plant growth and development even though there are no visible signs of water deficiency, resulting in reduced productivity ('Da Matta et al., 2004; '2Da Matta \& Ramalho, 2006). Coffee plants under drought present foliar wilt, whose symptom can occur faster or not according to the degree of tolerance to drought $\left({ }^{3}\right.$ Carvalho et al., 2016). Plants develop strategies to remain under the condition of drought, such as stomatal closure, alteration of the cuticular wax, root augmentation, osmotic adjustment and others. In the osmotic adjustment there is an increase in the endogenous content of osmolytes that are related to the preservation of cellular turgor. The permeability of the plasma membrane is affected by the drought that is accompanied by electrolyte leakage. This study aimed to characterize the morphological and physiological responses induced by water restriction in $C$. arabica plants.

\section{Results and Discussion}

Plants of $C$. arabica of the cultivars Bourbon Vermelho, Mundo Novo, Obatã, BA-10, Laurina and Geisha and of the variety Semperflorens kept in pots under greenhouse conditions were submitted to two cycles of drought. Plants of all treatments were irrigated continuously between each cycle. Each treatment consisted of three plants. In each cycle, the plants were evaluated for leaf temperature, electrolytic leakage, soil moisture content and foliar wilt symptom. The values of electrolytic leakage were obtained by: $V E=(E C 1 / E C 2)^{*} 100$. For the evaluation of leaf wilt a scale of notes was used, being 1 . no symptom, 2. partial wilt and 3. complete wilt (Image 1).
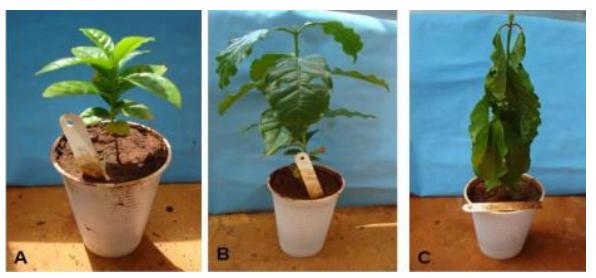

Image 1. Leaf wilt symptom scale in C. arabica plants. A. Note 1. plant without symptom, B. Note 2. plant with partial wilt and C. Note 3 . plant with complete foliar wilt.
In Cycle 1, all treatments under water restriction had 100 $\%$ of note 3 , complete leaf wilt, except for the genotypes Semperflorens and Laurina that responded, respectively, with 0 and $33.3 \%$ of note 3 . On the other hand, in Cycle 2, all treatments under water restriction had note 2, partial wilt, except for the cultivar Geisha that responded with $66.6 \%$ of note 3, complete wilt. In Cycle 1, foliar temperature varied, this was higher for the plants of Semperflorens, Mundo Novo and Obatã of the control treatments and for the Bourbon Vermelho, BA-10 and Geisha under water restriction, while Laurina had similar responses in both conditions. However, in Cycle 2, leaf temperature was higher for all control treatment plants, except for the BA-10 that was lower. In relation to the electrolytic leakage, in Cycles 1 and 2, it was higher for all genotypes under water restriction, except, respectively, for Obatã and Semperflorens, which had higher responses in the control (Chart 1).

Chart 1. Electrolytic leaching (\%) from plants of $C$. arabica under water restriction.

\begin{tabular}{|l|c|c|c|c|}
\hline \multirow{2}{*}{ Genotypes } & \multicolumn{2}{c|}{ Cycle 1 } & \multicolumn{2}{c|}{ Cycle 2 } \\
\cline { 2 - 5 } & H & RH & H & RH \\
\hline Bourbon Vermelho & $37.5( \pm 1.6)$ & $38.3( \pm 7.6)$ & $29.9( \pm 1.6)$ & $46.0( \pm 8.8)$ \\
\hline Semperflorens & $39.1( \pm 2.9)$ & $48.1( \pm 0.5)$ & $36.9( \pm 0.3)$ & $30.8( \pm 3.7)$ \\
\hline Mundo Novo & $35.9( \pm 0.9)$ & $40.5( \pm 7.4)$ & $33.5( \pm 4.6)$ & $48.0( \pm 26.0)$ \\
\hline Obatã & $33.8( \pm 2.4)$ & $30.9( \pm 5.3)$ & $26.7( \pm 3.9)$ & $28.8( \pm 2.5)$ \\
\hline BA-10 & $38.1( \pm 5.2)$ & $41.1( \pm 6.1)$ & $29.0( \pm 1.2)$ & $33.6( \pm 5.4)$ \\
\hline Laurina & $38.7( \pm 6.2)$ & $40.8( \pm 5.2)$ & $30.1( \pm 2.1)$ & $35.5( \pm 13.5)$ \\
\hline Geisha & $34.0( \pm 2.1)$ & $41.1( \pm 6.5)$ & $28.8( \pm 2.9)$ & $29.8( \pm 2.8)$ \\
\hline
\end{tabular}

$\mathrm{H}$ : Continuous hydration, $\mathrm{RH}$ : Water restriction

\section{Conclusions}

Among the genotypes studied, the plants of Semperflorens and Laurina presented higher tolerance to water restriction. Possibly, these two genotypes used the same strategy to maintain the leaf turgor under the water restriction.

\section{Acknowledgement}

To the National Council for Scientific and Technological Development (CNPq) for the PIBIC grant awarded.

${ }_{1}^{1}$ DaMatta, F.M Brazilian Journal Plant Physiology. 2004, 16, 1

${ }^{2}$ DaMatta, F.M.; Ramalho, J. D. C. Brazilian Journal Plant Physiology. 2006, 18, 55 .

${ }^{3}$ Carvalho, F.G.; Sera, G.H., Andreazi et al. Coffee Science, 2017, 12, 156. 